Lepr Rev (1992) 63, Supplement 23s-30s

\title{
The epidemiology of disability in leprosy including risk factors
}

\author{
W C S SMITH
}

\section{Introduction}

It is disability which sets leprosy apart from other diseases, ${ }^{1}$ and a control programme cannot be successful if it fails to control disability. Disability is a very relevant measurement of progress in leprosy control. ${ }^{2}$ To the lay person leprosy means deformity ${ }^{3}$ and leprosy without disability is often not recognized as leprosy by the general public, even in the untreated lepromatous stage. It is quite clear that disability is an important measure in the evaluation of control-however, to be able to use this fact, it is necessary to be able to define disability, and correctly measure it, and to understand its determinants and distribution. In particular, it is important to understand the evolutionary process of disability in individuals and populations in order to estimate the impact of various interventions on disability in leprosy.

\section{Definition and measurement of disability}

It is rare to find in the leprosy literature a definition of disability other than the alteration of function as opposed to deformity which is defined as the alteration of shape. Most of the disability literature in leprosy lists items rather than considers definitions and these lists include deformity as well as disability, and changes in anatomy and physiological function.

An International Classifications of Impairment, Disability and Handicap (ICIDH) has been developed ${ }^{4}$ in parallel to the development of the use of the term disability in the leprosy world. This classification introduces concepts of disability related to rehabilitation in contrast to the strictly descriptive definition used in leprosy. The International Classification uses the following definitions:

a. Impairment - Any loss or abnormality of psychological, physiological, or anatomical structure or function'-WHO, 1980;

b. Disability - Any restriction or lack (resulting from an impairment) of ability to perform an activity in the manner as within the range considered normal for a human being'-WHO, 1980;

c. Handicap - A disadvantage for a given individual resulting from an impairment or disability, that limits or prevents fulfilment of a role that is normal, depending on age, sex, and social and cultural factors for the individual'-WHO, 1980. 
It can be seen from these definitions that what leprologists call disabilities are probably regarded by the ICIDH definition as impairments.

Thus the whole system of approach to disability terminology in leprosy differs from that now recommended by the World Health Organization. The approach used in leprosy is suitable for measurement and description of disabilities, and for epidemiological purposes, however, it fails to incorporate the concepts of rehabilitation, which is a major deficiency. Thus a weakness in a muscle group may be seen as a disability to be corrected surgically rather than developing an understanding of what this functional loss means to that individual patient, if anything at all.

A number of scales of disability assessment have been developed ${ }^{5-7}$ and it is clear that none are considered adequate by all as new modifications are developed. ${ }^{8}$ It may be considered that no system is ideal when so many have been developed or, perhaps, that different scales are developed for different purposes. There are two major purposes for measurement of disability and each require different tools. The first is the simple grading of the level of disability - this can be carried out quickly in the field and gives a rough assessment of disability. The second is a measurement tool which is sensitive enough to measure change in disability. The first tool cannot do this but if the first purpose is the one required then the more detailed assessment is unnecessary. The exact measurement tool used for the assessment of change depends on what changes the observer wants to examine. However, there is still the need for a standard measure which can be used to compare disabilities between places and over time. The use of a variety of measurement tools makes it difficult to compare the experience in different programmes.

A very different approach to surveying disability is taken by the ICIDH system from that generally used in the field of leprosy. The survey begins with questions to the individual about function ability to see if that person has a disability. When a disability is identified in this way then further investigation is carried out to identify which impairment gives rise to the disability and whether the disability constitutes a handicap. This is an interesting approach which would identify the disabilities that are important to the patient rather than those which are important to the health worker. This approach certainly merits consideration by leprologists.

\section{Epidemiology of disability (impairment) in leprosy}

The well-recognized risk factors for disability in leprosy are listed in Table 1. In common with most disease processes, disability in leprosy increases with age. (See Figure 1, based on a data set from India. ${ }^{2}$ ) This observation is well known and well documented,,${ }^{9,10}$ as is the fact that disability rates are higher in men than in women.

Classification of leprosy is also related to the frequency of disability, being highest towards the lepromatous end of the spectrum (Figure 2). This is not a surprising observation given the pathogenesis of the disease. The age effect, however, is independent of the type of leprosy. Duration of disease is also noted to be a risk factor. ${ }^{10}$

The treatment of leprosy is related to disability in many studies, which show that those who are receiving treatment are more likely to be disabled than those who are not receiving treatment. ${ }^{10,11}$ Two explanations have been proposed, first that those disabled are more easily detected and more likely to be motivated to take treatment; and secondly that treatment may cause disability. This later controversial explanation has been 
Table 1. Risk factors for disability in leprosy

1 Age

2 Sex

3 Classification

4 Duration of disease

5 Site of skin lesions

6 Reversal reactions

7 Treatment

8 Socioeconomic factors

9 Educational attainment

10 Geographical factors

11 Ethnic group

12 Occupation

13 Method of case detection

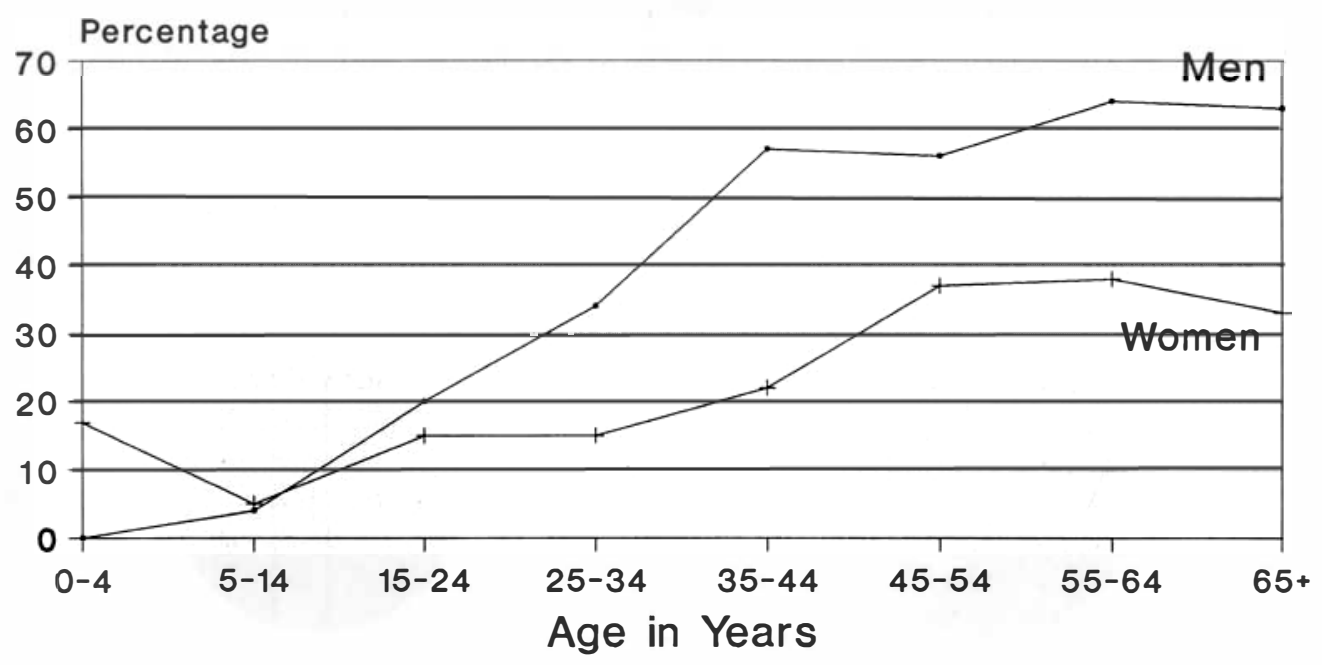

$\mathrm{N}=931$

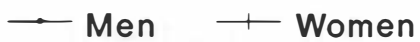

Figure 1. Percentage with impairment.

proposed during the monotherapy era and there is evidence that nerve damage occurs during MDT, ${ }^{12}$ but whether this is more frequent than during monotherapy or when untreated is not known (Figure 3).

Poor socioeconomic status and low educational attainment have both been identified as disability risk factors, ${ }^{10,11}$ but whether this is cause or effect is unclear, and may in individual patients be either or both. Occupation has also been identified as a risk factor, and this is not unexpected where those with heavy manual jobs or with occupations which 


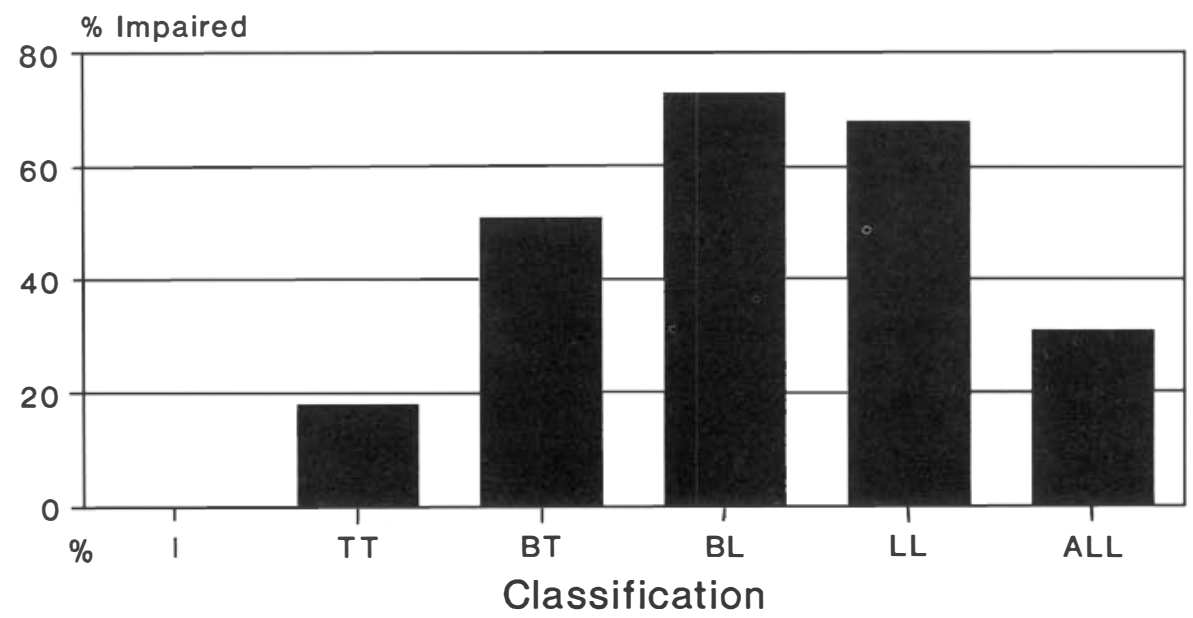

Series 1

Figure 2. Impairment by classification.

MB Cases on MDT

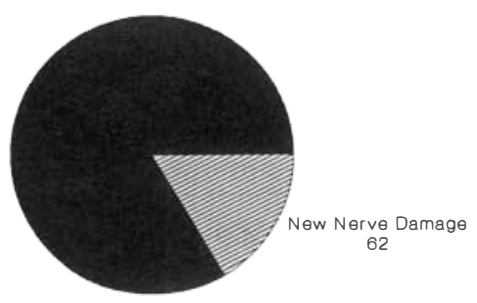

PB Cases on MDT

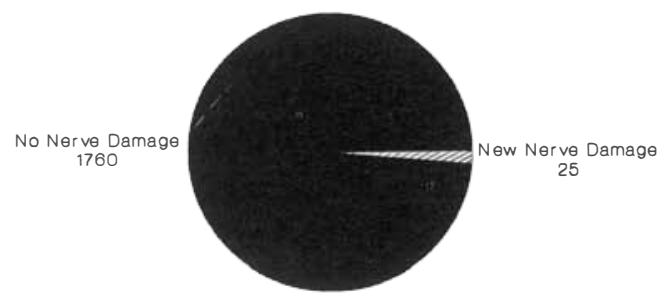

\section{1 patients}

Figure 3. New nerve damage during MDT.

involve walking for long distances are more susceptible to secondary disabilities. Ethnic group and geography have both been noted as important in disability rates within individual countries, but lack of standardization of methods is often a problem in interpreting studies between countries. Factors such as different distribution of classification may confound geographical differences in disability.

Different disability rates are noted by method of case detection (Figure 4) where voluntary reporting shows the highest rates. ${ }^{2}$ 


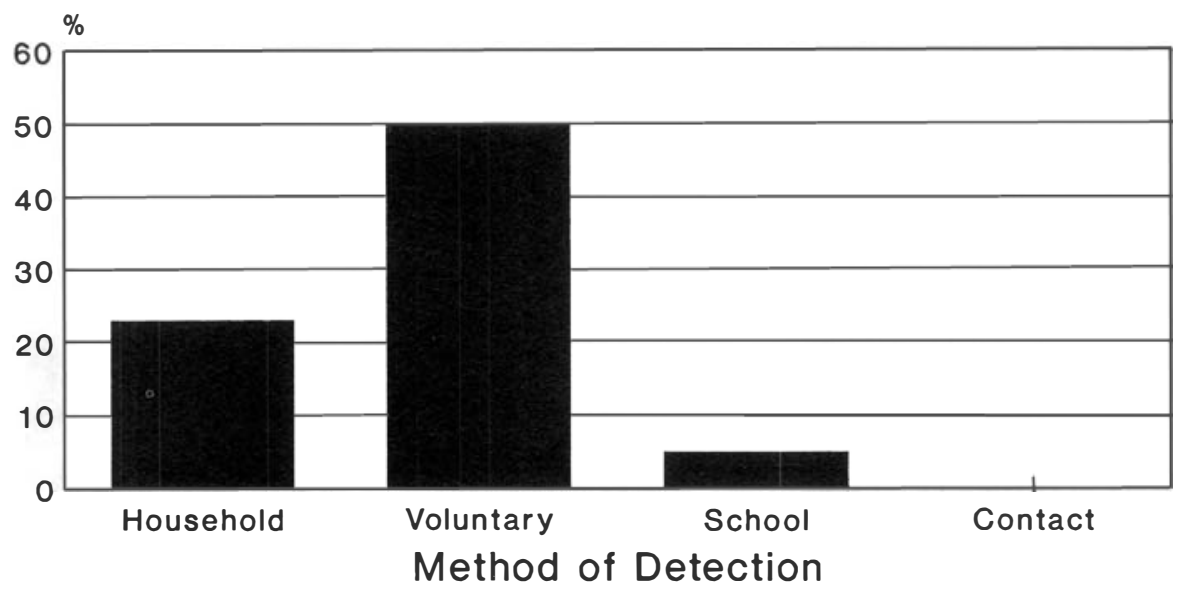

Series 1

Figure 4. Impairment rates.

\section{Trends in impairment rates}

The trends in impairment rates are important in evaluation of leprosy control programmes and a number of important points need to be emphasized. Firstly, as control programmes develop the impairment rates in newly-detected patients (Figure 5) decline. ${ }^{13}$ This would happen even if the treatment programme had no effect on disability and it is a mistake to attribute the effect to the programme without using a control group. This is because disabled patients are more easily detected and as programmes develop most new patients added are diagnosed earlier.

A second important point to note is that those with impairment naturally tend to deteriorate (Figure 6). The rate of deterioration varies by classification.

The current practice of deleting from treatment registers and releasing from control patients with impairment disguises the problem of disability in leprosy in a community, and this is especially true with the use of MDT. Figure 7, again based on data from India, shows the rapid decline in registered cases after the introduction of MDT but no similar decline in the prevalence of patients with impairment. ${ }^{13,14}$

\section{Prevention of disability}

This is an important element of control programmes which has recently been studied, ${ }^{15}$ where attention was focused on the leprologists' approach to disability. The ICIDH classification would suggest a broader approach to disability prevention at three levels: (1) prevention of impairment by early detection and treatment of disease and of acute nerve damage; (2) limitation or reversal of disability due to impairment using aids, appliances, surgery and patient education; (3) prevention of the transition from disability to handicap by public education, social and cultural adaptation and vocational training. 


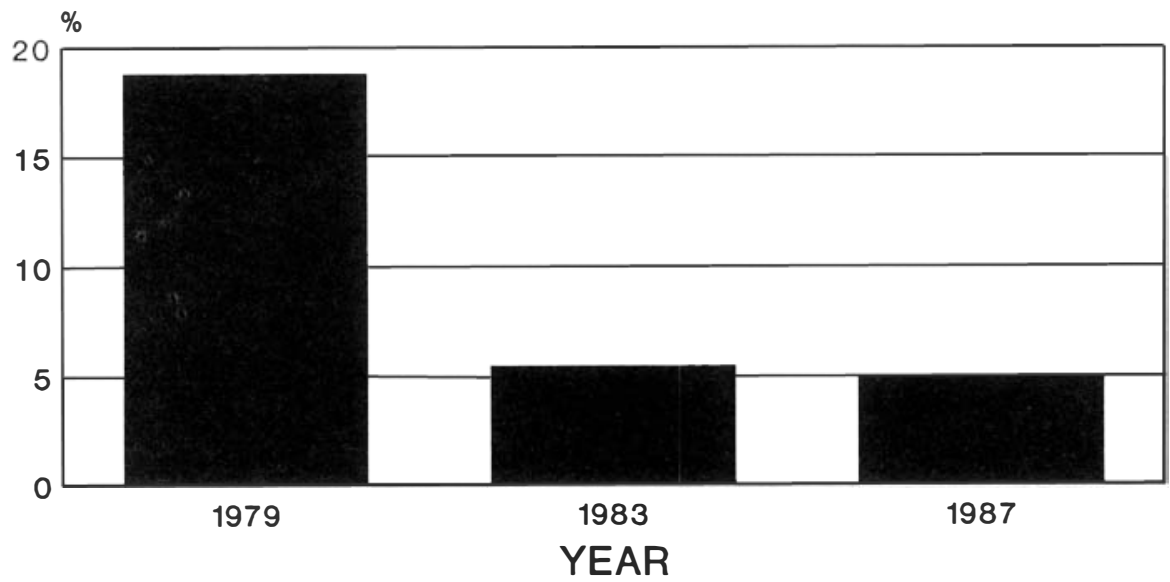

Series 1

Figure 5. Impairment in new patients.

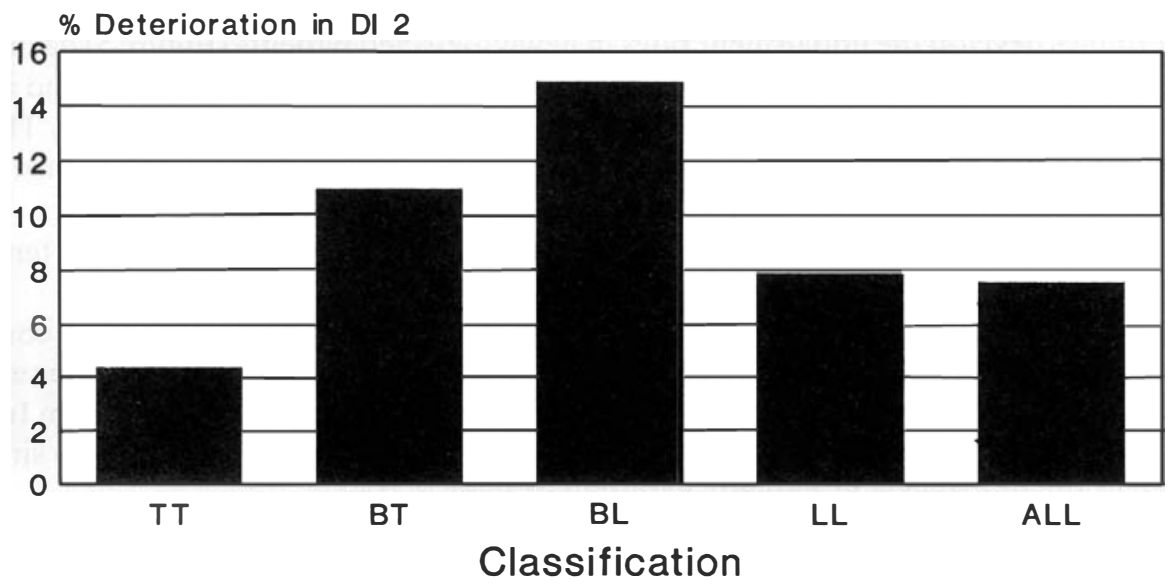

Series 1

19 improved, 28 Deteriorated

Figure 6. Deterioration in impairment (118 patients followed over 4 years). 


\section{Prevalence Rate of Leprosy}

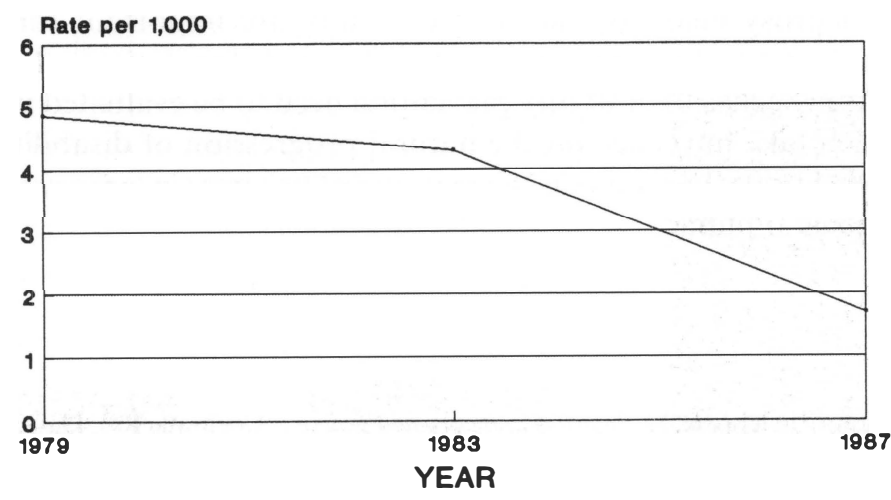

\section{Prevalence Rate of Impairment}

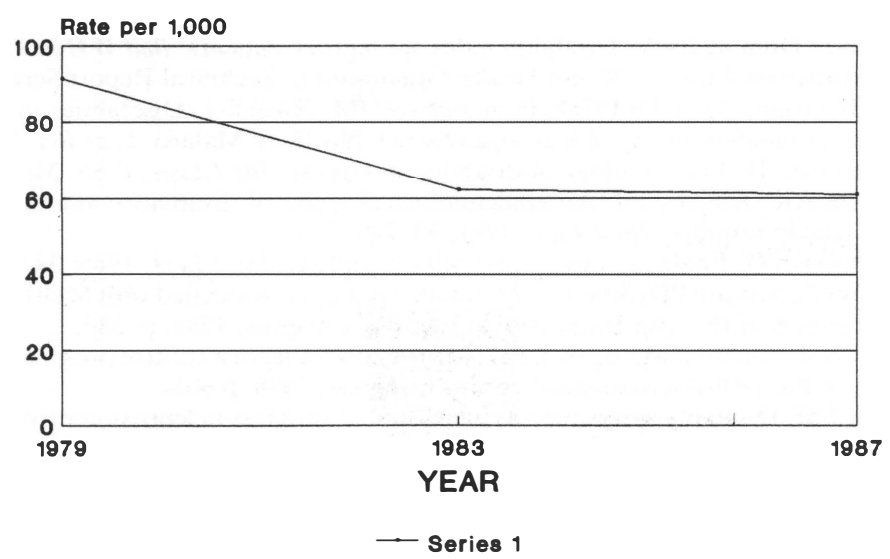

Figure 7. Prevalence changes-leprosy and impairment.

Important research questions are now being addressed as to the effectiveness of different methods of disability prevention and in particular to their cost-effectiveness. Studies are currently under way to look at these issues but it is important that analysis of these studies take account of the natural trends in disability and that proper controlled studies are designed.

\section{Conclusions}

Disability in leprosy is extremely important because to the patient and the public it is the disability that sets the leprosy patient apart. Standardized methods of measurement of 
disability still need to be developed and the approach adopted by the new International Classification of Impairments, Disability and Handicaps needs to be given consideration by those in the leprosy field. Measures of disability are important for evaluation of programmes, evaluation of treatments, to identify needs for patient education and for rehabilitation. Approaches to disability prevention need to be evaluated in terms of costeffectiveness which take into account the natural progression of disability and must be based on controlled trials. Disability is the measure of progress in leprosy control which is relevant to the general public.

\section{References}

1 Brand PW. Deformity in leprosy. In: Le prosy in theory and practice, Cochrane RG, Davey TF (eds), Bristol: John Wright and Sons, 1964, 2nd Edition, pp. 447-96.

2 Smith WCS, Antin US, Patole AR. Disability in leprosy: a relevant measurement of progress in leprosy. Lepr Rev, 1980; 51: 155-66.

${ }^{3}$ Srinivasan H, Dharmendra SH. Deformities in leprosy. In: Leprosy Vol 1. Dharmendra SH (ed), Kothari Medical Publishing House, Chapter 27, pp. 197.

4 World Health Organization. International Classification of impairments, disabilities and handicaps. Geneva: WHO, 1980.

5 WHO Expert Committee on Leprosy. World Health Organisation. Technical Report Series No $189,1960$.

${ }^{6}$ Bechelli LM, Martinez Dominguez V. Disability index for leprosy patients. Bull WHO, 1971; 44: 709-13.

7 WHO Expert Committee on Leprosy. World Health Organisation. Technical Report Series No 768, 1988.

8 Ponninghaus IM, Boerrigter G, Fine PEM, Ponninghaus JM, Russell J. Disabilities in leprosy patients ascertained in a total population survey in Karonga District, Northern Malawii. Lepr Rev, 1990; 61: 366-74.

9 Noordeen SK, Srinivasan H. Epidemiology of disability in leprosy. Int J Lepr, 1966; 34: 159-69.

10 Kushwah SS, Govila AK, Kushwah J. An epidemiological study of disabilities among leprosy patients attending leprosy clinic in Gwalior. Int J Lepr, 1981; 53: 240-7.

11 Noordeen SK, Srinivasan H. Epidemiology of disability in leprosy. Int J Lepr, 1966; 34: 170-4.

12 Parkhe SM, Smith WCS, Samson PD, Solomon M. Sudden paralysis associated with MultiDrug Therapy-a cautionary tale. Abstracts of the 13th International Leprosy Congress, 1988, p. 380.

13 Smith WCS, Parkhe SM, Solomon M, Samson PD. Leprosy disability in a control programme-trends over 10 years. Abstracts of the 13th International Leprosy Congress, 1988, p 603.

14 Smith WCS, Parkhe SM. Disability assessment as a measure of progress in leprosy control. Lepr Rev, 1986; 57: 251-9.

15 Watson JM. Disability control in a leprosy control programme. Lepr Rev, 1989; 60: 169-77. 